\title{
Cytoreductive nephrectomy with thrombectomy before targeted therapy improves survival for metastatic renal cell carcinoma with venous tumor thrombus: a single-center experience
}

Nienie $Q i^{1}$, Pengjie $\mathrm{Wu}^{2}$, Jinchao Chen ${ }^{1}$, Teng $\mathrm{Li}^{1}$, Xianghui Ning ${ }^{1}$, Jin Wang ${ }^{3}$ and Kan Gong ${ }^{4^{*}}$

\begin{abstract}
Background: The aim of the study is to evaluate the role of cytoreductive nephrectomy $(\mathrm{CN})$ with thrombectomy before targeted molecular therapy (TMT) on survival in metastatic renal cell carcinoma (mRCC) with venous tumor thrombus.

Methods: We performed a retrospective analysis of 47 patients treated in our center from April 2008 to October 2014. In the study, 20 patients underwent CN with thrombectomy followed by targeted therapy (group 1); 15 patients received targeted therapy alone (group 2); and 12 patients underwent CN with thrombectomy alone (group 3). The overall survival (OS) and cancer-specific survival (CSS) were calculated according to the Kaplan-Meier survival curve method, and prognostic variables were assessed by Cox regression analyses.

Results: The median follow-up times of group 1, group 2, and group 3 were 24.5, 12, and 6.5 months, respectively. During follow-up, in both group 1 and group 3, 12 patients died. In group 2, 14 patients died. The median OS of group 1, group 2, and group 3 was 22, 12, and 6 months, respectively $(P<0.001)$. Compared with surgery alone and targeted therapy alone, patients with cytoreductive surgery before targeted therapy had statistically better survival benefits $(P<0.001, P=0.009$, respectively). On univariate analysis, the number of metastatic sites $(P=0.004)$ was a statistically significant prognostic factor influencing OS.
\end{abstract}

Conclusions: Our single-center experience showed that $\mathrm{CN}$ with thrombectomy before targeted therapy improved the survival of patients with mRCC with venous tumor thrombus. The number of metastatic sites was an independent prognostic factor influencing OS.

Keywords: Renal cell carcinoma, Metastasis, Venous tumor thrombus, Cytoreductive surgery, Targeted molecular therapy

\footnotetext{
* Correspondence: gongkan_pku@126.com

${ }^{4}$ Department of Urology, Peking University First Hospital, Institute of Urology,

Peking University; National Urological Cancer Center, No. 8, Xishiku St.,

Xicheng Dist, Beijing 100034, China

Full list of author information is available at the end of the article
} 


\section{Background}

Venous tumor thrombus (VTT) occurs in approximately $5-10 \%$ of patients undergoing nephrectomy for renal cell carcinoma (RCC) [1]. In addition to venous involvement, $25 \%$ of patients with RCC have metastatic disease when diagnosed [2]. Patients with RCC and VTT should be considered for surgical intervention, irrespective of the extent of tumor thrombus at presentation [3]. Before the era of targeted therapy, two prospective randomized controlled trials had demonstrated the overall benefit of cytoreductive nephrectomy $(\mathrm{CN})$ in metastatic RCC $[4,5]$. A population-based study also showed the beneficial effect of $\mathrm{CN}$ on survival [6]. The emerging of targeted therapy offers more choices for $\mathrm{mRCC}$ and has prompted a reevaluation of cytoreductive surgery [7]. Tyrosine kinase inhibitor (TKI) had been shown to extend the progression-free survival and overall survival [8]. Differential expression of prognostic proteomic markers, such as VEGFR1, was found in primary tumor, VTT, and metastatic renal cell cancer tissue [9], suggesting that TKI alone may help improve the survival of mRCC with VTT.

Although $\mathrm{CN}$ with inferior vena cava (IVC) thrombectomy was performed with acceptable complication rates [10], it remains unclear whether surgery is still a good choice for concomitant mRCC with VTT. Thus, we retrospectively evaluated the benefits of $\mathrm{CN}$ with thrombectomy before targeted therapy in patients presenting with $\mathrm{mRCC}$ with VTT.

\section{Methods}

We reviewed the medical records of all patients who presented to our center from April 2008 to October 2014 for evaluation of or treatment for concomitant mRCC with VTT. During the study period, 61 patients presented with concomitant mRCC with VTT who had received no systemic therapy. Among them, 20 patients underwent $\mathrm{CN}$ with thrombectomy followed by TMT (combined therapy, group 1); 15 patients received TMT alone (group 2); 12 patients underwent $\mathrm{CN}$ with thrombectomy alone (group 3); and 2 refused any therapy. The treatment of the other 12 patients was uncertain. Patients in group 1, group 2, and group 3 had postoperative pathology or biopsy confirmed of RCC histology. Metastasis was confirmed by radiology. The following clinical characteristics of each patient were recorded: age, gender, ECOG PS (Eastern Cooperative Oncology Group performance score), tumor size, pathologic type, nuclear grade, venous thrombus level, number of metastatic sites, $\mathrm{T}$ stage and $\mathrm{N}$ stage. These characteristics were potential prognostic factors [11-14]. Staging was determined according to the 2009 AJCC staging system [15]. Nuclear grade was graded using the Fuhrman grading system [16]. Venous tumor extent was graded according to the Mayo Clinic grading system [17]. Nineteen patients received sorafenib (18 cases as first-line therapy and 1 case as second-line therapy following sunitinib). Sorafenib was administered at a dose of $400 \mathrm{mg}$ twice daily and continued until disease progression or the onset of an intolerable adverse drug event. The 19 patients received sunitinib (16 cases as first-line therapy and 3 cases as second-line therapy following sorafenib). Sunitinib was administered at a dose of $50 \mathrm{mg}$ once daily for 4 weeks, followed by 2 weeks off by repeated 6-week cycles. All the 19 patients were treated continuously until disease progression or unacceptable toxicities occurred. Pazopanib monotherapy was administered at a dose of $800 \mathrm{mg}$ once daily in 1 patient. No neoadjuvant targeted therapy was used. Informed consent was obtained from all individual participants included in the study. The study was approved by the institutional review board from Peking University First Hospital.

\section{Statistical analysis}

Likelihood ratio with chi-square and $t$ tests was used for comparisons between groups in categorical and continuous variables, respectively. OS (overall survival) and CSS (cancer-specific survival) curves were derived by the Kaplan-Meier method with the log-rank test. Each group was further compared with Kaplan-Meier curve. Univariate Cox hazards regression were applied to evaluate the value of prognostic factors including advanced age, gender, ECOG PS, pathological type, nuclear grade, venous thrombus level, $\mathrm{T}$ stage, $\mathrm{N}$ stage, and number of metastatic sites in predicting OS and CSS. All statistical analyses were performed using SPSS version 19 (SPSS Inc., Chicago, IL, USA). Statistical significance was set at $P<0.05$.

\section{Results}

Table 1 shows patient clinicopathological characteristics at diagnosis. The median age of group 1, group 2, and group 3 were 55(20-70), 58(26-72), and 61(46-71) years, respectively. There were no significant differences except gender, ECOG PS, nuclear grade, $\mathrm{N}$ stage, and number of metastatic sites. In group 1, 10 patients were T3a; 5 patients were T3b. The number of level 0 , level II, and level III thrombus was 12, 5, and 3, respectively. Lung metastasis, liver metastasis, bone metastasis, and adrenal metastasis appeared in 12, 4, 3, and 2 patients, respectively. In group 2, 4 patients were T3a; 8 patients were T3b. The number of level 0 , level I, level II, and level III thrombus was 4, 1, 3 and 7, respectively. Lung metastasis, liver metastasis, adrenal metastasis, bone metastasis, and pleura metastasis appeared in $10,5,4,3$, and 2 patients, respectively. In group 3, 7 patients were T3a; 1 patient was T3b; 1 patient was T3c. The number of level 0 , level I, level III, and level IV thrombus was 9, 1, 1 and 1, respectively. Lung metastasis, bone metastasis, liver 
Table 1 Patient demographics of group 1, group 2, and group 3

\begin{tabular}{|c|c|c|c|c|}
\hline & Group 1 & Group 2 & Group 3 & $P$ \\
\hline No & 20 & 15 & 12 & \\
\hline Gender, n (\%) & & & & $0.590^{a}, 0.022^{b}$ \\
\hline Male & 15(75.0\%) & $10(66.7 \%)$ & $12(100 \%)$ & \\
\hline Female & $5(25.0 \%)$ & $5(33.3 \%)$ & $0(0 \%)$ & \\
\hline Age, $n(\%)$ & & & & $0.486^{a}, 0.197^{b}$ \\
\hline$\geq 60$ & $7(35.0 \%)$ & $7(46.7 \%)$ & $7(58.3 \%)$ & \\
\hline$<60$ & $13(65.0 \%)$ & $8(53.3 \%)$ & $5(41.7 \%)$ & \\
\hline Pathologic type, $n(\%)$ & & & & $1.000^{a}, 0.360^{b}$ \\
\hline Clear cell & $16(80.0 \%)$ & $12(80.0 \%)$ & $11(91.7 \%)$ & \\
\hline Non-clear cell & $4(20.0 \%)$ & $3(20.0 \%)$ & $1(8.3 \%)$ & \\
\hline Nuclear grade, $n$ (\%) & & & & $0.005^{a}, 0.488^{b}$ \\
\hline $\mathrm{G} 1+\mathrm{G} 2$ & $3(15.0)$ & $9(60.0 \%)$ & $3(25.0 \%)$ & \\
\hline $\mathrm{G} 3+\mathrm{G} 4$ & $17(85.0 \%)$ & $6(40.0 \%)$ & $9(75.0 \%)$ & \\
\hline VT level, n (\%) & & & & $0.039^{a}, 0.900^{b}$ \\
\hline Above hepatic vein & $3(15.0 \%)$ & $7(46.7 \%)$ & $2(16.7 \%)$ & \\
\hline Below hepatic vein & $17(85.0 \%)$ & $8(53.3 \%)$ & 10(83.3\%) & \\
\hline Tumor size, $(\mathrm{cm} \pm \mathrm{SD})$ & $9.9 \pm 2.4$ & $10.8 \pm 4.0$ & $9.8 \pm 1.8$ & $0.439^{a}, 0.903^{b}$ \\
\hline T stage, $n(\%)$ & & & & $0.726^{a}, 1.000^{b}$ \\
\hline T3 & 15(75.0\%) & 12(80.0\%) & $9(75.0 \%)$ & \\
\hline T4 & $5(25.0 \%)$ & $3(20.0 \%)$ & $3(25.0 \%)$ & \\
\hline N stage, $n(\%)$ & & & & $0.061^{\mathrm{a}}, 0.252^{\mathrm{b}}$ \\
\hline NO & 13(65.0\%) & $5(33.3 \%)$ & 10(83.3\%) & \\
\hline N1 & $7(35.0 \%)$ & $10(66.7 \%)$ & $2(16.7 \%)$ & \\
\hline \multicolumn{2}{|c|}{ Number of metastatic sites, $n(\%)$} & & & $0.001^{a}, 0.586^{b}$ \\
\hline 1 & 18(90.0\%) & $6(40.0 \%)$ & 10(83.3\%) & \\
\hline$>1$ & $2(10.0 \%)$ & $9(60.0 \%)$ & $2(16.7 \%)$ & \\
\hline ECOG PS & & & & $0.015^{\mathrm{a}}, 0.742^{\mathrm{b}}$ \\
\hline 0 & $16(75.0 \%)$ & $6(40.0 \%)$ & $9(75.0 \%)$ & \\
\hline 1 & $4(25.0 \%)$ & $9(60.0 \%)$ & $3(25.0 \%)$ & \\
\hline
\end{tabular}

${ }^{a}$ Comparison between group 1 and group 2

${ }^{\mathrm{b}}$ Comparison between group 1 and group 3

metastasis, and adrenal metastasis appeared in 9, 3, 1, and 1 patient, respectively.

The median follow-up time of group 1, group 2, and group were 24.5 (range 3-66), 12 (range 2-33), and 6.5 (range 3-30) months. During follow-up, 12 patients died in both group 1 and group 3 . Fourteen patients died in group 2. The median OS of group 1, group 2, and group 3 was 22 (95\% CIs 4.5-39.5), 12 (95\% CIs 3.2-20.8), and 6 (95\% CIs $4.3-7.7)$ months, respectively $(P<0.001$, Fig. 1$)$. The median CSS of group 1, group 2, and group 3 was 45 , 19 , and 8 months, respectively $(P<0.001$, Fig. 2$)$. The median progression-free survival of group 1 and group 2 were 12 (range 1-66) and 9 (range 2-23) months, respectively. Compared with patients who underwent surgery alone or targeted therapy alone, patients with cytoreductive surgery before targeted therapy had statistically better overall survival benefits $(P<0.001$ and $P=$ 0.009 , respectively). Patients with combined therapy also had better CSS benefits. In a univariate Cox proportional hazards model to predict OS, we found that the number of metastatic sites was a significant predictor of OS (Table 2). Compared with patients with solitary metastasis, patients with more than one metastatic site had a 2.94-fold higher risk of overall mortality (95\% CIs 1.41-6.09, $P=0.004)$. However, the number of metastasis did not affect the probability of CSS (Table 2).

One patient in group 1 achieved complete remission. None of patients in group 2 achieved complete remission. The median treatment duration of sorafenib was 8 months. Adverse events were shown in Table 3. Most of them were grade 1-2 adverse events. The grade 3-4 major adverse events (4 cases) included hand-foot syndrome ( 2 cases), rash (1 case), and fatigue (1 case). All of them kept treatment with symptomatic support. The median treatment duration of sunitinib was 12 months. Adverse events were shown in Table 4. The grade 3-4 major adverse events (7 cases) included thrombocytopenia (3 cases), leukocytopenia (2 cases), hand-foot syndrome (1 case), and thyroid dysfunction (1 case). Six patients had dose decrement or drug discontinuation. All of them kept treatment with symptomatic support. The patient treated with pazopanib emerged with hand-foot syndrome, nausea, and vomit during treatment. After 16 months, he progressed with lung metastasis and withdrew from treatment.

\section{Discussion}

The combination of $\mathrm{CN}$ and systemic therapy plays an important role in the management of patients with mRCC. Retrospective studies suggest that mRCC patients with IVC tumor thrombus may experience improved survival after surgical resection and systemic therapy. These studies were conducted before the current era of targeted therapy, which, at present, represent a standard therapy for mRCC. In the era of targeted therapy, few researches explored this problem. Taekmin Kwon et al. found that surgical resection of the primary renal mass with IVC thrombus before use of TKI did not affect the overall mortality [18]. Conversely, Karin E et al. suggested that $\mathrm{CN}$ with IVC thrombectomy should be considered as an integral part of the treatment approach for patients with mRCC with IVC tumor thrombi [10]. However, proper treatment of mRCC with VTT has yet to be determined. Our study showed that compared with surgery alone and targeted therapy alone, cytoreductive surgery before targeted therapy improved the overall survival and cancer-specific survival of mRCC with VTT.

The prognosis was quite poor for the majority of patients with RCC with VTT when left untreated, 


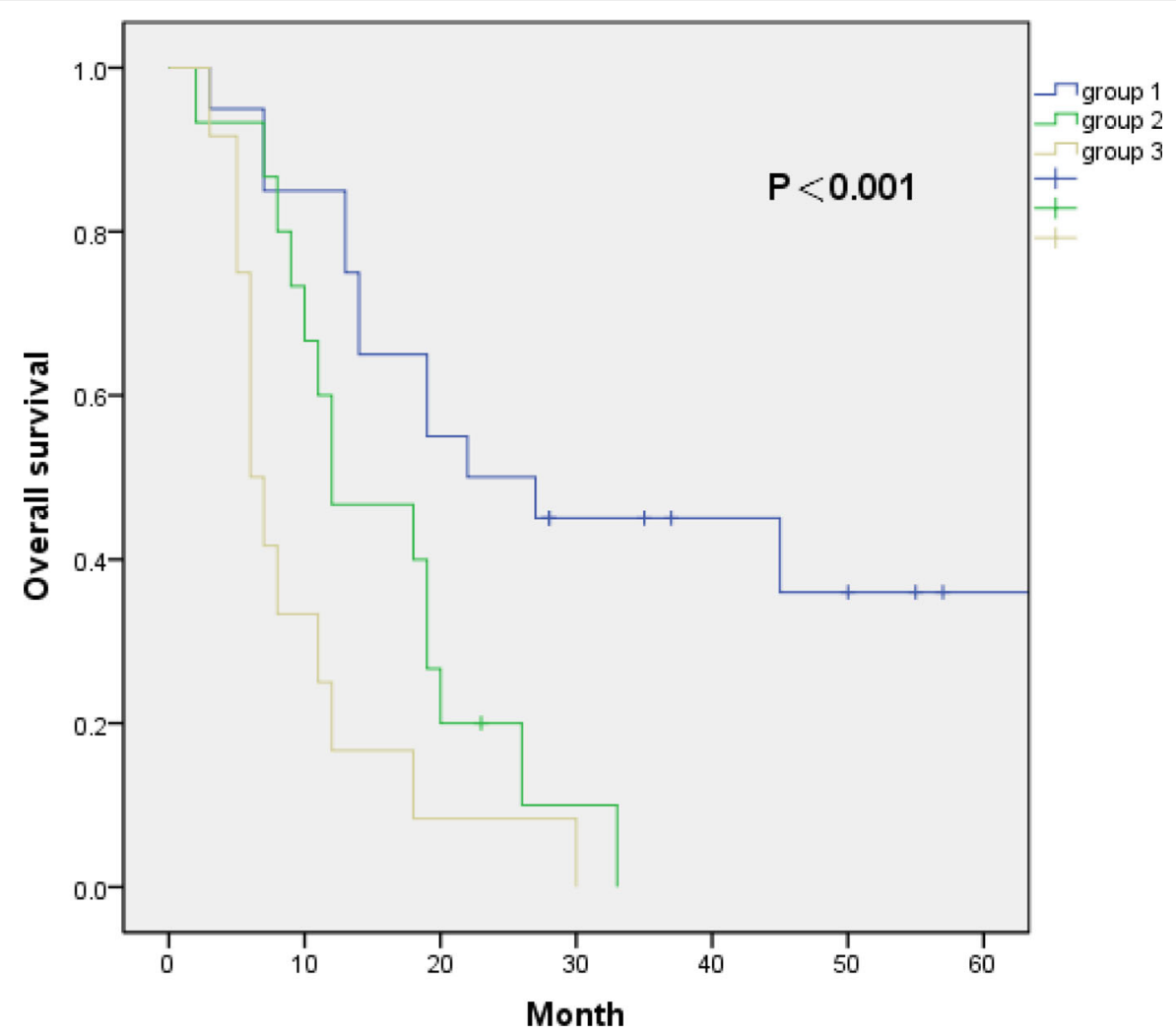

No. at risk

$\begin{array}{llllllll}\text { Group 1 } & 20 & 17 & 11 & 7 & 5 & 3 & 1 \\ \text { Group 2 } & 15 & 10 & 3 & 1 & 0 & & \\ \text { Group 3 } & 12 & 4 & 1 & 0 & & \end{array}$

Fig. 1 Overall survival of group 1, group 2, and group 3

especially for those with metastases. In patients presenting with metastatic disease, 1-year DSS (disease-specific survival) was 23\% (median DSS: 4 months) for those with thrombus below the diaphragm and 10\% (median DSS: 3 months) for those with thrombus above the diaphragm [19]. For those with distant metastases at the time of diagnosis who underwent surgery, 1-year survival was $60 \%$. This finding highlighted the importance of surgery on their prognosis. With the development of surgical skills, novel anesthetic technique, and hemodynamic monitor, the perioperative mortality and complications associated with nephrectomy with thrombectomy decreased to an acceptable level $[17,20]$. In some patients, surgery may help to relieve symptoms. However, the surgery was still challenging, and surgery-related morbidity or mortality could not be neglected. Bissada et al. reported higher perioperative mortality in patients with metastasis (33\%) versus patients without metastasis $(2 \%)$ [21]. Fortunately, all of the 32 patients survived surgery in our center. However, some patients may undergo disease progression during recovery from surgery and may not proceed to receive systemic therapy for their metastatic tumor burden [22]. In fact, we observed that some patients failed to receive targeted therapy after surgery for several reasons. Silberstein et al. [23] have demonstrated that patients with poor performance status are more likely to experience postoperative complications, and these patients tend not to receive systemic therapy on time after surgery. Culp et al. [24] identified seven risk factors that predicted inferior OS after $\mathrm{CN}$, including high lactate dehydrogenase activity, low albumin level, symptoms caused by metastatic disease, liver metastasis, retroperitoneal adenopathy, supradiaphragmatic adenopathy, and a greater than cT3 disease. Patients with $\geq 4$ risk factors did not appear to benefit from $\mathrm{CN}$. Based on the present study, it seems that patients' general condition and performance status should be used to best define candidates for $\mathrm{CN}$ with VTT. While the risk of perioperative complications outweighed the potential benefits, cytoreductive surgery should not be the first option considered. 


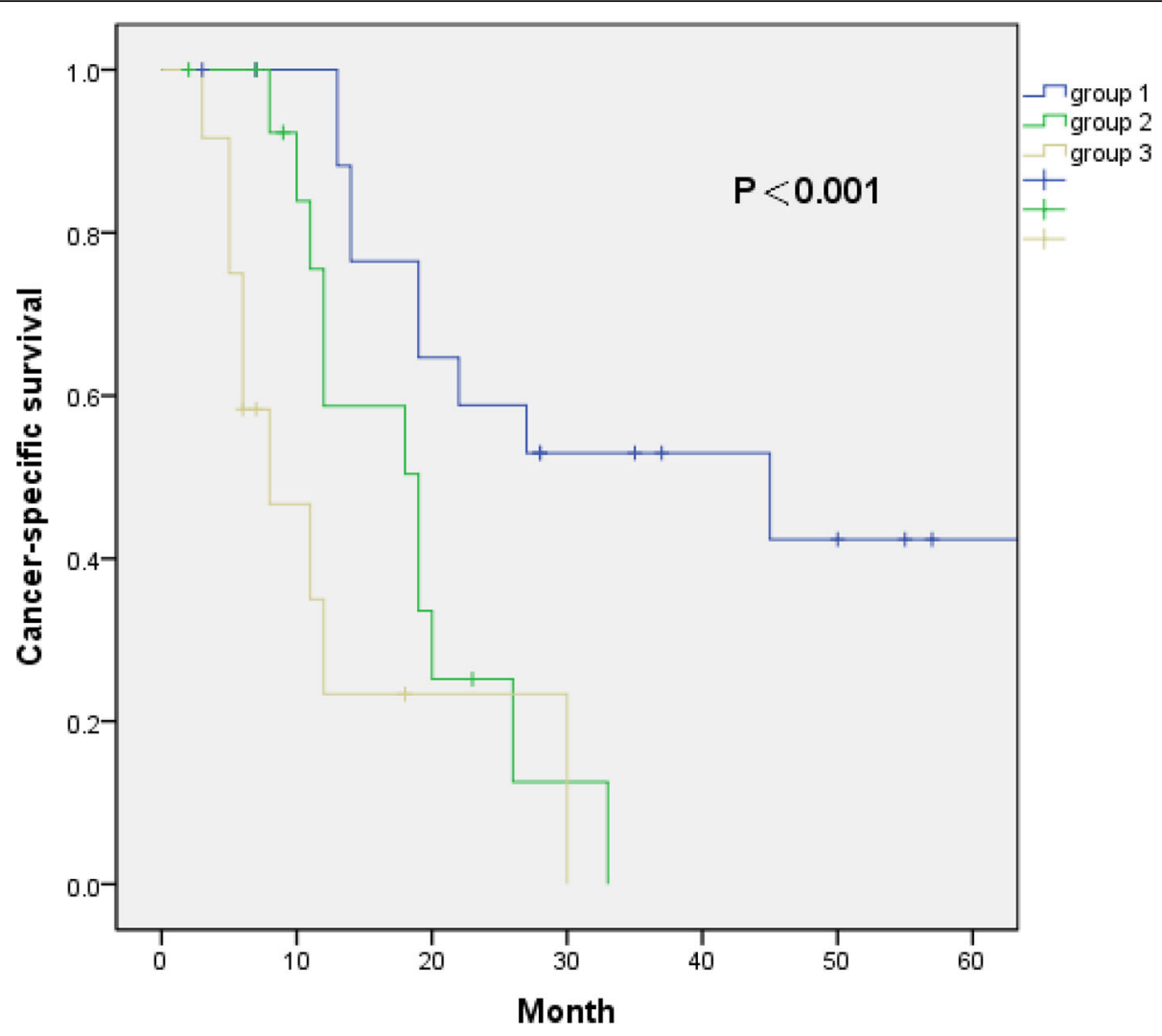

Fig. 2 Cancer-specific survival of group 1, group 2, and group 3

On univariate Cox regression analysis, pathologic type, nuclear grade, and venous tumor thrombus level were not significantly associated with survival. In contrast, more than one metastatic site was an independent prognostic factor of a poor OS. In fact, a previous study had already shown that the number of metastatic sites affected the survival rates of the patients with mRCC [25]. This may be owing to the more disease burden and worse functional status. More studies are needed to help ameliorate the poor prognosis.

Our study had some limitations. The number of patients was low and follow-up time was short. Because of

Table 2 Univariate analysis of potential prognostic factors for OS and CSS

\begin{tabular}{|c|c|c|c|c|}
\hline \multirow[b]{2}{*}{ Variables } & \multicolumn{2}{|l|}{ Univariate for OS } & \multicolumn{2}{|l|}{ Univariate for CSS } \\
\hline & $\mathrm{HR}(95 \% \mathrm{Cl})$ & $P$ value & $\mathrm{HR}(95 \% \mathrm{Cl})$ & $P$ value \\
\hline Age ( $\geq 60$ vs. $<60)$ & $1.56(0.82-2.96)$ & 0.178 & $1.53(0.73-3.21)$ & 0.256 \\
\hline Gender (female vs. male) & $1.02(0.48-2.17)$ & 0.958 & $1.07(0.45-2.51)$ & 0.883 \\
\hline ECOG PS (1 vs. 0) & $0.59(0.29-1.20)$ & 0.145 & $0.64(0.29-1.41)$ & 0.267 \\
\hline Pathological type (non-clear cell vs. clear cell) & $0.71(0.28-1.83)$ & 0.480 & $0.76(0.26-2.18)$ & 0.605 \\
\hline Nuclear grade (G3 + G4 vs. G1 + G2) & $0.84(0.43-1.64)$ & 0.608 & $0.65(0.31-1.40)$ & 0.273 \\
\hline VT level (above hepatic vein vs. below hepatic vein) & $1.67(0.71-3.03)$ & 0.302 & $1.36(0.58-3.20)$ & 0.482 \\
\hline T stage (T4 vs. T3) & $1.50(0.70-3.20)$ & 0.294 & $1.63(0.69-3.87)$ & 0.264 \\
\hline N stage (N1 vs. N0) & $1.32(0.69-2.54)$ & 0.407 & $1.63(0.77-3.47)$ & 0.203 \\
\hline Number of metastatic sites (more than 1 vs. 1) & $2.94(1.41-6.09)$ & 0.004 & $2.14(0.86-5.34)$ & 0.103 \\
\hline \multicolumn{5}{|l|}{ Combined therapy } \\
\hline TMT alone & $2.69(1.20-6.02)$ & 0.017 & $3.25(1.28-8.27)$ & 0.013 \\
\hline Surgery alone & $5.64(2.39-13.29)$ & $<0.001$ & 7.05(2.60-19.11) & $<0.001$ \\
\hline
\end{tabular}


Table 3 Adverse events of sorafenib

\begin{tabular}{llll}
\hline Adverse events & Grade $1-2, n$ & Grade $3-4, n$ & $n, \%$ \\
\hline Diarrhea & 11 & 0 & $11(57.9 \%)$ \\
Hand-foot syndrome & 9 & 2 & $11(57.9 \%)$ \\
Hypertension & 8 & 0 & $8(42.1 \%)$ \\
Alopecia & 7 & 0 & $7(36.8 \%)$ \\
Rash & 5 & 1 & $6(31.6 \%)$ \\
Fatigue & 1 & 1 & $2(10.5 \%)$ \\
Nausea and vomit & 1 & 0 & $1(5.3 \%)$ \\
Anemia & 1 & 0 & $1(5.3 \%)$ \\
Leukocytopenia & 1 & 0 & $1(5.3 \%)$ \\
Liver dysfunction & 1 & 0 & $1(5.3 \%)$ \\
Elevation of uric acid & 1 & 0 & $1(5.3 \%)$ \\
\hline
\end{tabular}

its retrospective nature, the study lacked randomization and has selection bias. Many factors may influence the decision to undergo cytoreductive surgery before targeted therapy. One obvious bias is that patients choosing targeted therapy alone have a higher percentage of multiple metastatic sites. Pierorazio PM has already shown that patients with widespread metastatic burden may not benefit from surgery and are likely to choose conservative management [26]. A population-based study based on the surveillance, epidemiology, and end results database revealed a similar result [27]. Some patients even failed to receive targeted therapy after surgery for various reasons. In additional, these patients had not been resected of metastatic sites, even though complete metastasectomy provides benefits in terms of OS, CSS, and delay of systemic therapy [3]. Moreover, in our study, the population was small, so we did not introduce multivariable Cox analysis. Large-scale, randomized, and prospective studies are needed to determine the effect on survival of $\mathrm{CN}$ with thrombectomy before targeted therapy.

Table 4 Adverse events of sunitinib

\begin{tabular}{llll}
\hline Adverse events & Grade $1-2, n$ & Grade $3-4, n$ & $n, \%$ \\
\hline Thrombocytopenia & 12 & 3 & $15(78.9 \%)$ \\
Thyroid dysfunction & 13 & 1 & $14(73.7 \%)$ \\
Hand-foot syndrome & 12 & 1 & $13(68.4 \%)$ \\
Leukocytopenia & 9 & 2 & $11(57.9 \%)$ \\
Hypertension & 9 & 0 & $9(47.4 \%)$ \\
Fatigue & 8 & 0 & $8(42.1 \%)$ \\
Diarrhea & 8 & 0 & $8(42.1 \%)$ \\
Anorexia & 7 & 0 & $7(36.8 \%)$ \\
Palpebral edema & 6 & 0 & $6(31.6 \%)$ \\
Oral mucositis & 5 & 0 & $5(26.3 \%)$ \\
Hypophosphatemia & 3 & 0 & $3(15.8 \%)$ \\
Liver dysfunction & 1 & 0 & $1(5.3 \%)$ \\
\hline
\end{tabular}

\section{Conclusions}

Compared with cytoreductive surgery alone and targeted therapy alone, $\mathrm{CN}$ with thrombectomy before targeted therapy may offer better survival for mRCC with VTT. Our single-center experience suggested a positive role for cytoreductive surgery followed by targeted therapy in these patients.

\section{Abbreviations}

CN: Cytoreductive nephrectomy; CSS: Cancer-specific survival; DSS: Disease-specific survival; ECOG PS: Eastern Cooperative Oncology Group performance score; IVC: Inferior vena cava; mRCC: Metastatic renal cell carcinoma; OS: Overall survival; TKl: Tyrosine kinase inhibitor; TMT: Targeted molecular therapy; VTT: Venous tumor thrombus

\section{Acknowledgements \\ Not applicable.}

\section{Funding}

This work was supported by grants from the Beijing Natural Science Foundation (7142160).

\section{Availability of data and materials}

Please contact author for data requests.

\section{Authors' contributions}

NQ conceived the study, participated in its design, collected the data, performed the statistical analysis, and drafted the manuscript. PW participated in its design, collected the data, and performed the statistical analysis. JC participated in its design, collected the data, and performed the statistical analysis. TL participated in its design and performed the statistical analysis. XN participated in its design and performed the statistical analysis. JW participated in its design and collected the data. KG participated in its design, collected the data, performed the statistical analysis, and helped to draft the manuscript. All authors read and approved the final manuscript.

\section{Competing interest}

The authors declare that they have no competing interests.

\section{Consent for publication}

Written informed consent was obtained from the patient for the publication of this report.

Ethics approval and consent to participate

Informed consent was obtained from all individual participants included in the study. The study was approved by the institutional review board from Peking University First Hospital.

\section{Author details}

${ }^{1}$ Department of Urology, Peking University First Hospital, Institute of Urology, Peking University, Beijing, China. 'Department of Urology, Beijing Hospital, Beijing, China. ${ }^{3}$ Department of cardiac surgery, Peking University First Hospital, Beijing, China. ${ }^{4}$ Department of Urology, Peking University First Hospital, Institute of Urology, Peking University; National Urological Cancer Center, No. 8, Xishiku St., Xicheng Dist, Beijing 100034, China.

Received: 11 May 2016 Accepted: 14 December 2016

Published online: 05 January 2017

\section{References}

1. Rabbani F, Hakimian P, Reuter VE, Simmons R, Russo P. Renal vein or inferior vena caval extension in patients with renal cortical tumors: impact of tumor histology. J Urol. 2004;171:1057-61.

2. Gupta K, Miller JD, Li JZ, Russell MW, Charbonneau C. Epidemiologic and socioeconomic burden of metastatic renal cell carcinoma (mRCC): a literature review. Cancer Treat Rev. 2008;34:193-205.

3. Ljungberg B, Bensalah $\mathrm{K}$, Canfield S, Dabestani S, Hofmann F, Hora M, et al. EAU guidelines on renal cell carcinoma: 2014 update. Eur Urol. 2015;67:913-24. 
4. Mickisch GH, Garin A, van Poppel H, de Prijck L, Sylvester R. Radical nephrectomy plus interferon alfa-based immunotherapy compared with interferon alfa alone in metastatic renal-cell carcinoma: a randomized trial. Lancet. 2001;358:966-70.

5. Flanigan RC, Salmon SE, Blumenstein BA, Bearman SI, Roy V, McGrath $P C$, et al. Nephrectomy followed by interferon alfa-2b compared with interferon alfa-2b alone for metastatic renal-cell cancer. $N$ Engl J Med. 2001;345:1655-9.

6. Zini L, Capitanio U, Perrotte P, Jeldres C, Shariat SF, Arjane P, et al. Population-based assessment of survival after cytoreductive nephrectomy versus no surgery in patients with metastatic renal cell carcinoma. Urology. 2009;73:342-6.

7. You D, Jeong IG, Ahn JH, Lee DH, Lee JL, Hong JH, et al. The value of cytoreductive nephrectomy for metastatic renal cell carcinoma in the era of targeted therapy. J Urol. 2011;185:54-9.

8. van der Veldt AA, Haanen JB, van den Eertwegh AJ, Boven E. Targeted therapy for renal cell cancer: current perspectives. Discov Med. 2010;10: 394-405.

9. Laird A, O'Mahony FC, Nanda J, Riddick AC, O'Donnell M, Harrison DJ, et al. Differential expression of prognostic proteomic markers in primary tumor, venous tumor thrombus and metastatic renal cell cancer tissue and correlation with patient outcome. PLoS One. 2013;8(4):e60483.

10. Westesson KE, Klink JC, Rabets JC, Fergany AF, Klein EA, Stephenson AJ, et al. Surgical outcomes after cytoreductive nephrectomy with inferior vena cava thrombectomy. Urology. 2014;84:1414-9.

11. Tilki D, Nguyen HG, Dall'Era MA, Bertini R, Carballido JA, Chromecki T, et al. Impact of histologic subtype on cancer-specific survival in patients with renal cell carcinoma and tumor thrombus. Eur Urol. 2014;66:577-83.

12. Ciancio G, Manoharan M, Katkoori D, De Los SR, Soloway MS. Long-term survival in patients undergoing radical nephrectomy and inferior vena cava thrombectomy: single-center experience. Eur Urol. 2010;57:667-72.

13. Martínez-Salamanca Jl, Huang WC, Millán I, Bertini R, Bianco FJ, Carballido JA, et al. Prognostic impact of the 2009 UICC/AJCC TNM staging system for renal cell carcinoma with venous extension. Eur Urol. 2011;59:120-7.

14. Patard JJ, Leray E, Cindolo L, Ficarra V, Rodriguez A, De La Taille A, et al. Multi-institutional validation of a symptom based classification for renal cell carcinoma. J Urol. 2004;172:858-62.

15. Edge SB, Compton CC. The American Joint Committee on Cancer: the 7th edition of the AJCC cancer staging manual and the future of TNM. Ann Surg Oncol. 2010;17:1471-4.

16. Fuhrman SA, Lasky LC, Limas C. Prognostic significance of morphologic parameters in renal cell carcinoma. Am J Surg Pathol. 1982;6:655-63.

17. Abel EJ, Thompson RH, Margulis V, Heckman JE, Merril MM, Darwish OM, et al. Perioperative outcomes following surgical resection of renal cell carcinoma with inferior vena cava thrombus extending above the hepatic veins: a contemporary multicenter experience. Eur Urol. 2014;66:584-92.

18. Kwon T, Lee JL, You D, Jeong IG, Song C, Ahn H, et al. Impact of surgery on the prognosis of metastatic renal cell carcinoma with IVC thrombus received TKI therapy. J Surg Oncol. 2014;110:145-50.

19. Reese AC, Whitson JM, Meng MV. Natural history of untreated renal cell carcinoma with venous tumor thrombus. Urol Oncol. 2012;31:1305-9.

20. Parekh DJ, Cookson MS, Chapman W, Harrell Jr F, Wells N, Chang SS, et al. Renal cell carcinoma with renal vein and inferior vena caval involvement: clinicopathological features, surgical techniques and outcome. J Urol. 2005; 173:1897-902.

21. Bissada NK, Yakout HH, Babanouri A, Elsalamony T, Fahmy W, Gunham M, et al. Long-term experience with management of renal cell carcinoma involving the inferior vena cava. Urology. 2003;61:89-92.

22. Wood CG. The role of cytoreductive nephrectomy in the management of metastatic renal cell carcinoma. Urol Clin North Am. 2003:30:581-8.

23. Silberstein $\mathrm{J}$, Adamy A, Maschino AC, Ehdaie B, Garg T, Favaretto RL, et al. Systematic classification and prediction of complications after nephrectomy in patients with metastatic renal cell carcinoma (RCC). BJU Int. 2012;110: 1276-82.

24. Culp SH, Tannir NM, Abel EJ, Margulis V, Tamboli P, Matin SF, et al. Can we better select patients with metastatic renal cell carcinoma for cytoreductive nephrectomy? Cancer. 2010;116:3378-88.

25. Mekhail TM, Abou-Jawde RM, Boumerhi G, Malhi S, Wood L, Elson P, et al. Validation and extension of the Memorial Sloan-Kettering prognostic factors model for survival in patients with previously untreated metastatic renal cel carcinoma. J Clin Oncol. 2005:23:832-41.
26. Pierorazio PM, McKiernan JM, McCann TR, Mohile S, Petrylak D, Benson MC. Outcome after cytoreductive nephrectomy for metastatic renal cell carcinoma is predicted by fractional percentage of tumor volume removed. BJU Int. 2007:100:755-9.

27. Whitson JM, Reese AC, Meng MV. Factors associated with surgery in patients with renal cell carcinoma and venous tumor thrombus. BJU Int. 2011;107:729-34.

\section{Submit your next manuscript to BioMed Central and we will help you at every step:}

- We accept pre-submission inquiries

- Our selector tool helps you to find the most relevant journal

- We provide round the clock customer support

- Convenient online submission

- Thorough peer review

- Inclusion in PubMed and all major indexing services

- Maximum visibility for your research

Submit your manuscript at www.biomedcentral.com/submit
C) Biomed Central 